\title{
Research on the Risk Analysis Method of Social Stability of Major Engineering Projects in the Process of New-type Urbanization
}

\author{
Hao Wang \\ School of Civil Engineering and Architecture, Jishou University, Zhangjiajie 427000, Hunan China \\ Wha0121@163.com
}

Keywords: Urbanization, Engineering projects, Risks to social stability, Analysis method

\begin{abstract}
The 13th five-year plan is a crucial period for China's transformation and development. The social contradictions accumulated over a long period of extensive development have gradually become prominent. Therefore, maintaining social stability is particularly important for ensuring the stable development of the economy and society. This paper studies the risk analysis method of social stability of engineering project from the aspects of risk investigation method, risk factor identification, risk estimation and risk level judgment, risk prevention and solution measures. The research on the risk analysis method of social stability of engineering projects provides theoretical support and practical guidance for improving government management system, improving government management and service level.
\end{abstract}

\section{Introduction}

The 13th five-year plan is a critical period for China to build a well-off society in an all-round way, and also a transitional development period with both opportunities and challenges. For a long time, the social contradictions accumulated due to extensive development have become increasingly prominent. It is particularly important to maintain social stability to ensure the stable development of economy and society. However, the deepening of the new urbanization process and the continuous expansion of urban scale, the implementation of urban infrastructure projects such as school, hospital and public transport facilities. There is no way to avoid the unstable factors caused by the safety and health, ecological environment, project construction management and so on. If not handled properly, local people are likely to be dissatisfied, and arouse social contradictions and group adverse events, resulting in social disorder and unstable people's hearts [1]. In order to avoid the prevention, reduction, control and cope with the possible social stability risks at the source [2], the analysis method of social stability risks of engineering projects was studied. It provides theoretical support and practical guidance for government departments to improve management system, innovate management methods, and improve service level. It is of great significance for speeding up the construction of new urbanization, building a socialist harmonious society and realizing the goal of building a moderately prosperous society in all respects as scheduled [3].

\section{Risk analysis methods for social stability}

The risk analysis of social stability of engineering project uses a variety of management science and technology. The method of combining quantitative and qualitative evaluation with comprehensive and technical evaluation and empirical judgment is adopted. Analysis was carried out in accordance with the process of identifying social stability risk factors, identifying stakeholders, identifying major social stability risk factors and judging their degree.

\subsection{Investigate and identify risk stage}

Through the use of literature collection, field observation, questionnaire survey, personal interview and other appropriate and effective methods, understand and collect data on stakeholders involved in the natural, social environment of the project area and the risk of similar projects guided by the attitude media of grass-roots organizations. The main risk types and risk factors of the project were 
identified by using risk factors control checklist, risk identification questionnaire and other methods.

\subsection{Estimate risk judge risk level}

The risk level of the project is estimated through comprehensive analysis by using risk factor control checklist, subjective probability experts estimate, risk probability-impact matrix, risk index calculation method and participatory evaluation method.

\subsection{Measures to prevent and defuse risks}

The paper mainly puts forward effective measures to alleviate the risk factors of social stability at all stages of the project. To sort out and divide the responsible subjects and assisting units of measures in each period, clarify the responsible subjects and assisting units, and determine the implementation time and requirements of the division of responsibilities. Efforts should be made to fully implement relevant measures to reduce the impact of social stability risks and achieve the goal of controllable risks and low impact [4].

\section{Social stability risk survey methods}

As the basic work and an important part of risk analysis, risk investigation provides relevant field survey data for risk identification, risk estimation, risk level judgment, risk prevention and resolution measures. The methods of risk investigation are divided into three categories, namely, comprehensive survey, sample survey and case survey. The risk survey can be conducted in various forms, such as literature collection, field survey, questionnaire survey, visit to the public, holding symposium and public opinion analysis [5].

(1) Acquisition work: Understand the basic situation of the project to the construction party, and conduct research on the written documents such as the report of license opinions involved in the construction and operation of the project. A comprehensive collection of various documents related to project monitoring and preparation, including national, provincial, municipal and county social and economic development and urban construction planning documents, project planning and design special documents.

(2) Site survey: The scope of project implementation was surveyed, especially the main control points along the line and the scope of land expropriation and demolition were carefully observed. To investigate the distribution of surrounding residents and other social environment, listened to the introduction of relevant personnel, and the project area of the people started to ask.

(3) Questionnaire survey: To conduct public opinion consultation on the project, and conduct questionnaire survey on the masses of the project site by designing reasonable questionnaires. The focus, opinions and Suggestions of the general public and the affected population on the project are systematically grasped.

(4) Individual interview and panel discussion: In the major towns and villages in the area where the project is located, the local people were organized to have open discussions, listened to the opinions of the participants and had in-depth exchanges. At the same time, we visited the villagers along the road and communicated with some of them.

(5) Social investigations: Visit relevant departments such as the maintenance and stability office of the owner unit and some village committees or neighborhood committees in the project area. A questionnaire survey was conducted among local residents.

(6) Other surveys: Make use of media resources such as network newspaper to know and pay attention to relevant situation and public opinion.

(DExpert argumentation: After completing the above research and forming the preliminary draft of the research report, experts and scholars in the field of engineering management, safety evaluation and social management were invited. It also includes people who are familiar with and concerned about the project and community cadres who have been engaged in social management 
for a long time. The social risk and its impact of the project are analyzed in the form of expert consultation argumentation meeting.

\section{Identification of risk factors for social stability}

After a visit to the main street and village committee in the area where the project is located, the possible causes of social conflicts and the risk factors of social stability during the construction and operation of the project are discussed. Focus on the vital interests of related interest groups, and investigate and analyze the opinions and requirements of the masses. Ensure smooth construction and operation of the project.

There are many methods to identify risk factors, such as the comparison table method, the expert interview method and field trip method. Take the risk factor comparison table method as an example, through contrast specific risk factors, using the method such as workshops, from policy planning and approval procedures for the project, land and housing expropriation scheme, Technical and economic programs, Ecological environmental impact, project construction management, Economic and social impact, Safety in production and public safety, Social compatibility etc. Eight aspects has carried on the thorough analysis, identify the risk factors impacting the social stability in the project.

\section{Social stability risk assessment and risk rating judgment}

Risk estimation is the process of assessing the identified risk and making a comprehensive analysis and estimation of the possibility and impact of risk events. The content includes the estimation of risk probability, risk impact degree and risk occurrence time. Since the risk database of the project is not complete before implementation, the comprehensive evaluation method based on expert experience is adopted to evaluate the overall risk of the project. The major risk factors of the identified project are evaluated by using semi-quantitative matrix evaluation method. The definition, description and quantitative criteria of risk impact degree, risk degree and risk occurrence probability are proposed, and risk matrix is given based on three variables.

Risk judgment is to estimate the overall initial risk of the project comprehensively on the basis of single-factor risk analysis and compare it with the evaluation standard of given risk level. The process is to determine the initial risk level and the priority of risk prevention, and to decide whether to take appropriate preventive measures.

\section{Measures to prevent and defuse social stability risks}

In order to prevent and mitigate the risk of project implementation from the source, according to the actual situation and characteristics of the proposed project, the objective and strategy of risk prevention and resolution are formulated aiming at the main and key risk factors; The corresponding measures for risk prevention and mitigation are proposed, which mainly include comprehensive and special measures, as well as measures for preventing risks at the source and handling risks in a timely manner. A cooperative unit that is responsible for implementing safeguards. Clear guard duty time node and specific work content, ensure the risk can be managed within the effective time limit to minimize the dissonant factors. According to the overall goal of the project construction, improve the risk control ability, reduce the potential risk harm, analyze and select reasonable risk prevention measures.

\section{Conclusion}

According to the process of "identifying and sequencing social stability risk factors - identifying and sequencing stakeholders - identifying major social stability risk factors and judging their degree - proposing measures and recommendations”, the risk analysis method of social stability is divided 
into three steps. The basic method of social stability risk analysis is studied from four aspects of risk investigation method, risk factor identification, risk estimation and risk level judgment, risk prevention and countermeasures.(Scientific research project of Hunan Province Education Department, ID: 16C1340)

\section{References}

[1]Guo Xiuyun, Adding "Social Stability Risk Assessment" into Assessment of Important Project, Forum on Science and Technology in China,vol.12,pp. 18-22+46, 2012.

[2]Wang Ying, Consideration on the implementation of social stability risk assessment of major fixed asset investment projects, Chinese Consulting Engineers, vol.8, pp. 19-21, 2014.

[3]Wu Gaofei, The correct understanding of building a moderately prosperous society in all respects, Journal of Dalian Official, vol.3, pp. 10-11, 2013.

[4]Xu Chengbin, Li Kai meng and Peng Zhenwu, New Framework of Project Social Unrest Risk Assessment Oriented by Problem Solution, Technology Economics, vol.33, pp. 83-91, 2014.

[5]Lu Chuan, Research on key technology of social stability risk analysis for highway construction project, Modern Transportation Technology, vol.11, pp. 85-88, 2014. 